\title{
The Interaction of Supertyphoon Maemi (2003) with a Warm Ocean Eddy
}

\author{
I-I LiN AND CHUN-ChIEH Wu \\ Department of Atmospheric Sciences, National Taiwan University, Taipei, Taiwan \\ KerRy A. EMANUEL \\ Program in Atmospheres, Oceans, and Climate, Massachusetts Institute of Technology, Cambridge, Massachusetts \\ I-HUAN LEE \\ Institute of Marine Geology and Chemistry, National Taiwan Sun Yat-Sen University, Kaohsiung, Taiwan \\ Chau-Ron Wu and Iam-Fei Pun \\ Department of Earth Science, National Taiwan Normal University, Taipei, Taiwan
}

(Manuscript received 28 September 2004, in final form 2 March 2005)

\begin{abstract}
Understanding the interaction of ocean eddies with tropical cyclones is critical for improving the understanding and prediction of the tropical cyclone intensity change. Here an investigation is presented of the interaction between Supertyphoon Maemi, the most intense tropical cyclone in 2003, and a warm ocean eddy in the western North Pacific. In September 2003, Maemi passed directly over a prominent $(700 \mathrm{~km} \times$ $500 \mathrm{~km}$ ) warm ocean eddy when passing over the $22^{\circ} \mathrm{N}$ eddy-rich zone in the northwest Pacific Ocean. Analyses of satellite altimetry and the best-track data from the Joint Typhoon Warning Center show that during the $36 \mathrm{~h}$ of the Maemi-eddy encounter, Maemi's intensity (in 1-min sustained wind) shot up from 41 $\mathrm{m} \mathrm{s}^{-1}$ to its peak of $77 \mathrm{~m} \mathrm{~s}^{-1}$. Maemi subsequently devastated the southern Korean peninsula. Based on results from the Coupled Hurricane Intensity Prediction System and satellite microwave sea surface temperature observations, it is suggested that the warm eddies act as an effective insulator between typhoons and the deeper ocean cold water. The typhoon's self-induced sea surface temperature cooling is suppressed owing to the presence of the thicker upper-ocean mixed layer in the warm eddy, which prevents the deeper cold water from being entrained into the upper-ocean mixed layer. As simulated using the Coupled Hurricane Intensity Prediction System, the incorporation of the eddy information yields an evident improvement on Maemi's intensity evolution, with its peak intensity increased by one category and maintained at category- 5 strength for a longer period $(36 \mathrm{~h})$ of time. Without the presence of the warm ocean eddy, the intensification is less rapid. This study can serve as a starting point in the largely speculative and unexplored field of typhoon-warm ocean eddy interaction in the western North Pacific. Given the abundance of ocean eddies and intense typhoons in the western North Pacific, these results highlight the importance of a systematic and in-depth investigation of the interaction between typhoons and western North Pacific eddies.
\end{abstract}

\section{Introduction}

The interaction between tropical cyclones and ocean features, including warm ocean eddies and currents, has been identified, among others, as an important area of

Corresponding author address: Dr. Chun-Chieh Wu, Department of Atmospheric Sciences, National Taiwan University, No. 1, Sec. 4, Roosevelt Rd., Taipei 106, Taiwan.

E-mail: cwu@typhoon.as.ntu.edu.tw research into tropical cyclone intensity change (Hong et al. 2000; Shay et al. 2000; Goni and Trinanes 2003; Kaplan and DeMaria 2003; Emanuel et al. 2004). This issue was especially noted in connection with the unanticipated rapid intensification of Hurricane Opal (1995) observed during its encounter with a warm ocean eddy (Marks et al. 1998; Hong et al. 2000; Shay et al. 2000). From observational studies of Hurricanes Opal, Mitch, and Bret in the Atlantic, it is generally found that rapid intensification (typically from Saffir-Simpson category 
1 to 4 within 24-36 h) was observed when these hurricanes passed over warm ocean features (Shay et al. 2000; Goni and Trinanes 2003). It is also found that when ocean eddy information is incorporated into the coupled cyclone-ocean models, estimates of hurricane intensity can be improved markedly (Hong et al. 2000; Emanuel et al. 2004). However, many issues still remain unresolved and need to be explored in this relatively new field of research.

First, there are few studies on tropical cyclone-ocean eddy interaction in the northwest Pacific Ocean where intense tropical cyclones occur most frequently. Each year, about 6-10 typhoons of category 4 or 5 emerge in the western North Pacific. These severe typhoons are direct threats to the half-billion people living near the coast of east Asia. The high frequency of strong typhoons striking these regions can be partly attributed to the large area of warm sea surface temperature and corresponding large potential intensity (Emanuel 1995). Nevertheless, it remains unclear why some storms reach higher intensity than others.

It is well known that the western North Pacific is a region where prominent warm oceanic features exist, such as the Kuroshio warm current and ocean eddies in two eddy-rich zones (Yasuda et al. 1992; Qiu 1999; Roemmich and Gilson 2001; Hwang et al. 2004). In these two zones, both warm and cold eddies are frequently observed throughout the year (Yasuda et al. 1992; Qiu 1999; Roemmich and Gilson 2001; Hwang et al. 2004). The northern eddy zone (Yasuda et al. 1992) is located in the Kuroshio extension region $\left(30^{\circ}-40^{\circ} \mathrm{N}, 140^{\circ} \mathrm{E}-\right.$ $180^{\circ} \mathrm{W}$ ) southeast of Japan, while the southern eddy zone (Qiu 1999; Roemmich and Gilson 2001; Hwang et al. 2004) is located in the North Pacific Subtropical Countercurrent region $\left(18^{\circ}-25^{\circ} \mathrm{N}, 122^{\circ}-160^{\circ} \mathrm{E}\right)$ near the center of the western subtropical gyre. Eddies in the northern eddy rich zone are Kuroshio extensions (or rings), similar to the Gulf Stream rings in the Atlantic, and originate from the western boundary currents (Richard 1981; Pickard and Emery 1990; Yasuda et al. 1992). According to Qiu (1999), the southern eddy zone eddies originate from the baroclinic instability of the weak flow between the westward North Equatorial Current and the eastward Subtropical Countercurrent. In particular, the belt along $22^{\circ} \mathrm{N}$ is where eddies most frequently occur (Qiu 1999; Hwang et al. 2004). Thus, given the abundant ocean features and frequent occurrences of intense typhoons, it is logical to ask what role these ocean features play in the intensity evolution of the western North Pacific typhoons. So far, other than the recent brief observational analysis relating Typhoon Imbudo's intensification to warm ocean features
(Goni and Trinanes 2003), very little has been published on this subject.

Second, though rapid intensification has been observed during tropical cyclone-warm ocean feature encounters, favorable atmospheric conditions also exist. For example, when Hurricane Opal encountered the warm eddy, Opal was also under a favorable upperlevel atmospheric trough interaction condition (Bosart et al. 2000). As such, the extent to which the warm eddy contributed to the rapid intensification is not clear. We need to establish whether the rapid intensification would still take place if the warm eddy were not present. Is the presence of warm eddies the sole factor for rapid intensification?

Third, the existing literature (Schade 1997; Hong et al. 2000; Shay et al. 2000; Goni and Trinanes 2003; Emanuel et al. 2004) focuses very much on the role warm ocean features play in intensification, but there has been little investigation into the role warm ocean features play in sustaining tropical cyclone intensity. If warm ocean features can also play a role in sustaining a cyclone's high intensity after rapid intensification, then the potential threat from the tropical cyclone would increase. If, however, warm ocean features do not contribute to intensity maintenance, then the tropical cyclone intensity may drop sharply after reaching its peak, and therefore the potential risk would become lower. As such, it is also necessary to study the role warm ocean features play in maintaining tropical cyclone intensity.

Although virtually all studies of ocean eddy interaction have so far focused on the role of warm eddies, it should be noted that cold eddies should have at least as much influence on the tropical cyclone intensity change. Since the ocean feedback on tropical cyclone intensity varies nearly as the square of the unperturbed ocean mixed-layer depth (Schade and Emanuel 1999), a unit decrease in ambient mixed-layer depth exerts more influence on storm intensity than a unit increase does. In practice, forecasting rapid intensification must also concern itself with the problem of false alarms.

In September 2003, Typhoon Maemi encountered three warm ocean eddies in the southern eddy zone of the western North Pacific, including one of the most prominent warm ocean eddies in the southern eddy zone during that time (Fig. 1). After the eddy encounter, Maemi was observed to develop into the most intense supertyphoon of 2003. Based on the synergy of multiple remote sensing data, the Coupled Hurricane Intensity Prediction System (CHIPS) model (Emanuel 1999; Emanuel et al. 2004), and the U.S. Naval Research Laboratory's (NRL) North Pacific Ocean Nowcast/Forecast System (NPACNFS) operational ocean 


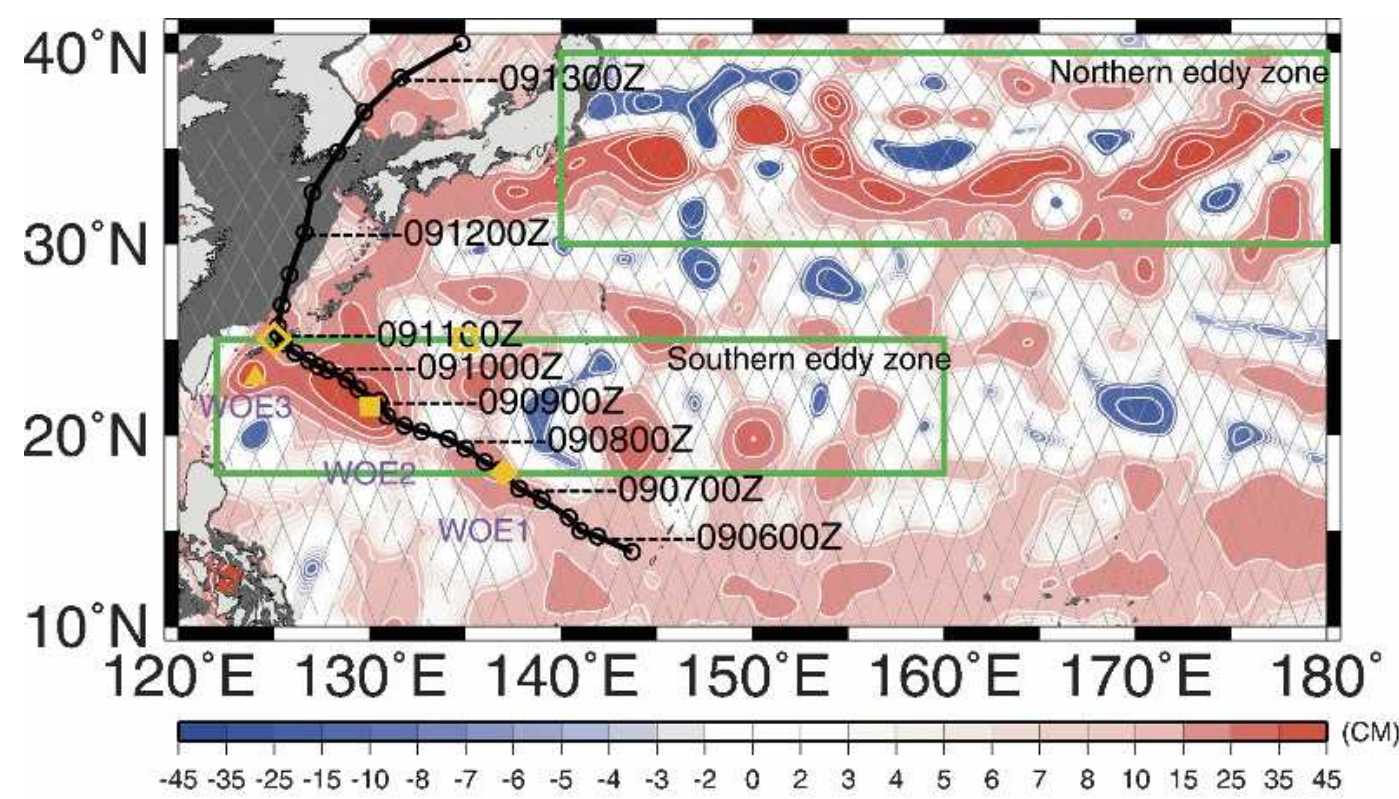

\section{tj_20030827-0905}

FIG. 1. Composite of NASA's TOPEX/Poseidon and Jason-1 altimetry measurements for one cycle (10 days) between 27 Aug and 5 Sep 2003 showing the pre-Maemi SSHA. Maemi's trajectory and locations of the two eddy-rich zones (northern eddy zone and southern eddy zone) are overlaid. Locations of the five vertical profiles [three eddy centers (WOE-1: solid diamond; WOE-2: solid square; WOE-3: solid triangle); eddy peripheral (blank diamond); and the reference/background (blank square)] in Fig. 3 are also depicted. As the current altimetry algorithm is less accurate in the shallow waters, the SSHA measurements in regions of bathymetry $<200 \mathrm{~m}$ are not used and are shown in dark gray (Fu and Cazenave 2001). The land areas are depicted in light gray.

model output (Ko et al. 2003), we study the interaction between Maemi and warm eddies with considerations of the aforementioned unresolved issues. The available coincident/collocated multiple remote sensing datasets include satellite altimetry sea surface height anomaly (SSHA) data from the Topography Experiment for Ocean Circulation (TOPEX)/Poseidon and Jason-1 missions (Fu et al. 1994) and the cloud-penetrating sea surface temperature data from the Tropical Rainfall Measuring Mission (TRMM) Microwave Imager (TMI) (Wentz et al. 2000). Besides traditional observations and National Centers for Environmental Prediction (NCEP) model analyses, satellite SSHA and sea surface temperature data are also used as inputs to the CHIPS model, while the NPACNFS model is used to provide the upper-ocean thermal structure. Typhoon track and intensity observations are based on the best-track data from the Joint Typhoon Warning Center (JTWC).

The following section describes typhoon tracks and pretyphoon eddy characteristics. Observational aspects of the Maemi-eddy interaction are documented in section 3. Section 4 presents and discusses the CHIPS model results. Discussions based on a comparison of the results from Maemi with previous tropical cyclone- eddy intensification cases are detailed in section 5 , and conclusions are given in section 6 .

\section{Typhoon tracks and pretyphoon eddy characteristics in the western North Pacific}

\section{a. Track of Maemi}

Maemi formed in the central North Pacific, with its central position located at $13.9^{\circ} \mathrm{N}, 143.7^{\circ} \mathrm{E}$, at 1800 UTC 5 September 2003. It then traveled northwestward across the western part of the North Pacific during 6-10 September. After passing the Okinawa Trough at 0000 UTC 11 September, it headed northward to the East China Sea before striking the southern part of the Korean peninsula at 1200 UTC 12 September 2003. After crossing the Korean peninsula, it eventually dissipated over the Sea of Japan at 0600 UTC 13 September (Fig. 1).

\section{b. Pre-Maemi SSHA and the sea surface temperature distribution}

As pointed out by Shay et al. (2000) and Goni et al. (2003), owing to the strong solar heating of the sea surface during the summer months, the ocean surface 


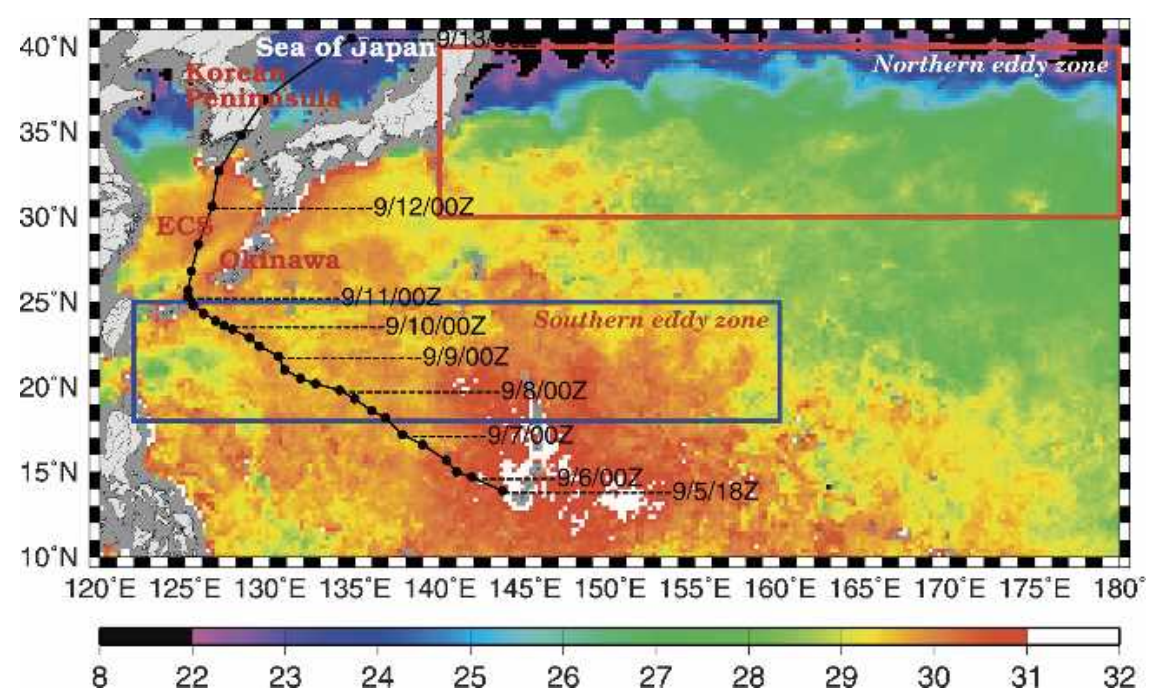

FIG. 2. (a) Composite of the TMI and AMSR-E passes during 3-5 Sep 2003 illustrating the pre-Maemi sea surface temperature distribution. Maemi's trajectory and the locations of the two eddy-rich zones are overlaid.

usually exhibits uniformly warm sea surface temperature. Therefore, it is difficult to use sea surface temperature data to identify eddies. Satellite SSHA measurements have proven to be very effective in identifying ocean eddies and to quantify eddy characteristics (Pickard and Emery 1990; Qiu 1999; Roemmich and Gilson 2001; Hwang et al. 2004) since it has the high accuracy of 1-2 cm for every 10-day cycle (http:// topex-www.jpl.nasa.gov). In this work, the SSHA data derived from the TOPEX/Poseidon and the newly available (from January 2002) Jason-1 satellite are used to identify ocean eddies. Figure 1 depicts the preMaemi SSHA condition from the composite of TOPEX/ Poseidon and Jason-1 measurements for one cycle during 27 August-5 September. Here TOPEX/Poseidon and Jason-1 SSHA data are composited together to maximize the use of available SSHA measurements; the nominal along-track spatial resolution is $5.5 \mathrm{~km}$.

As shown in Fig. 1, it is evident that mesoscale cold and warm eddies are mostly found in the aforementioned two eddy-rich zones, with clear negative $(<-8$ $\mathrm{cm})$ and positive $(>15 \mathrm{~cm})$ SSHAs. In the northern eddy zone, strings of warm and cold eddies with a typical scale of 100-200 km in diameter are observed. Such eddy characteristics are consistent with existing knowledge of Kuroshio extension eddies (Yasuda et al. 1992; Qiu 1999; Roemmich and Gilson 2001). Similarly, over the southern eddy zone, quite a few (order of 10) warm and cold eddies are present. In particular, three warmocean eddies (hereafter referred to as WOE-1, WOE-2, and WOE-3) are of relevance to our study. WOE-1 is characterized by an average SSHA of $15-25 \mathrm{~cm}$, with a size of around $400 \mathrm{~km} \times 200 \mathrm{~km}$. WOE-2 is the most prominent eddy in the southern eddy zone, with an average SSHA between 35 and $45 \mathrm{~cm}$ and a size of 700 $\mathrm{km} \times 500 \mathrm{~km}$. WOE-3 is located right next to WOE-2, with a diameter of about $200 \mathrm{~km}$ and an average SSHA of about $25-35 \mathrm{~cm}$ (Fig. 1). Tracing back for 2 months (figure not shown), it can be found that these three eddies are nearly stationary, with a very slow westwardpropagating speed of about $8-12 \mathrm{~km}$ per day. These attributes are typical of the southern eddy zone intense eddies (i.e., SSHA >14 cm) (Roemmich and Gilson 2001; Lee 2003; Hwang et al. 2004). The lifespan of these eddies is in general around 200-300 days (Lee 2003).

The pretyphoon sea surface temperature condition is illustrated using a composite of the TMI and Advanced Microwave Sounding Radiometer for the Earth Observing System (AMSR-E) passes (Wentz et al. 2000, 2003) during 3-5 September 2003 (Fig. 2). Similar to SSHA, sea surface temperature measurements from both TMI and AMSR-E are composited together to maximize the use of available sea surface temperatures. As shown in Fig. 2, eddies and background are both characterized by a sea surface temperature of around $30^{\circ} \mathrm{C}$, indicating the difficulty in distinguishing them by sea surface temperature alone.

\section{c. Pretyphoon upper-ocean thermal structure}

In the absence of in situ upper-ocean depthtemperature profiles over the vast western North $\mathrm{Pa}$ cific, profiles from the U.S. Naval Research Laboratory's NPACNFS nowcast model output are used. NPACNFS is a full 26-sigma-level ocean model with 
near-real time operational assimilation of comprehensive satellite observations. Through the Modular Ocean Data Assimilation System (MODAS), satellite altimetry and sea surface temperature data are assimilated. Figure 3 depicts the pretyphoon (1200 UTC 5 September 2003) upper-ocean temperature profiles of the three eddy centers together with a profile on the periphery and a reference/background profile beyond the eddy region. The locations of these five profiles are depicted in Fig. 1. It is evident from Fig. 3 that eddies are characterized by their distinctly thicker layer of warm water than the noneddy background. More specifically, in the eddy region, the depth of the water with temperature above $26^{\circ} \mathrm{C}$ extends downward to about $120-130 \mathrm{~m}$. In contrast, outside the eddy region, the warm water $\left(\sim 26^{\circ} \mathrm{C}\right.$ ) only extends downward to $40 \mathrm{~m}$ or so (Fig. 3), while the water temperature declines sharply to as low as $21^{\circ} \mathrm{C}$ at $100 \mathrm{~m}$. The distribution on the eddy periphery lies between the eddy centers and the background, with warm water below $26^{\circ} \mathrm{C}$ extending to $75 \mathrm{~m}$.

\section{Observational results}

Maemi was first identified as a tropical storm located to the south of the southern eddy zone (Fig. 1). It then headed northwestward toward the southern eddy zone, passing directly over WOE-1, WOE-2, and the northern periphery of WOE-3 during 7-11 September (Fig. 1). Maemi's intensity evolution based on JTWC's besttrack data is depicted in Fig. 4. According to several ocean regions (Fig. 1) Maemi passed over, five periods can be defined. The first period (P1), from 0600 UTC 5 September to 1800 UTC 6 September, is the incipient development period while Maemi was in the central North Pacific (Figs. 1, 2, and 4). The second period (P2), from 1800 UTC 6 September to 0000 UTC 8 September, is the period when Maemi passed over WOE-1. During this period, Maemi intensified from 28 to 37 $\mathrm{m} \mathrm{s}^{-1}$, reaching category-1 intensity (Figs. 1 and 4). The third period (P3), from 0000 UTC 8 September to 1200 UTC 8 September, is brief as Maemi passed the region in between WOE-1 and WOE-2, while it gradually intensified by 4 to $41 \mathrm{~m} \mathrm{~s}^{-1}$ (Figs. 1 and 4). The fourth period (P4), from 1200 UTC 8 September to 1200 UTC 11 September, is the period when Maemi passed WOE-2 and the northern periphery of WOE-3 (Figs. 1, 4, and 5). As Maemi encountered WOE-2 (Fig. 5), rapid intensification ensued. Within the $39-\mathrm{h}$ period of 1200 UTC 8 September to 0300 UTC 10 September, as Maemi moved over the core of WOE-2 (while the 850$250 \mathrm{mb}$ vertical wind shear was rather small, less than 5 $\mathrm{m} \mathrm{s}^{-1}$ during this period; figure not shown), its intensity shot up from 41 to $77 \mathrm{~m} \mathrm{~s}^{-1}$ (Figs. 4 and 5). This inten-

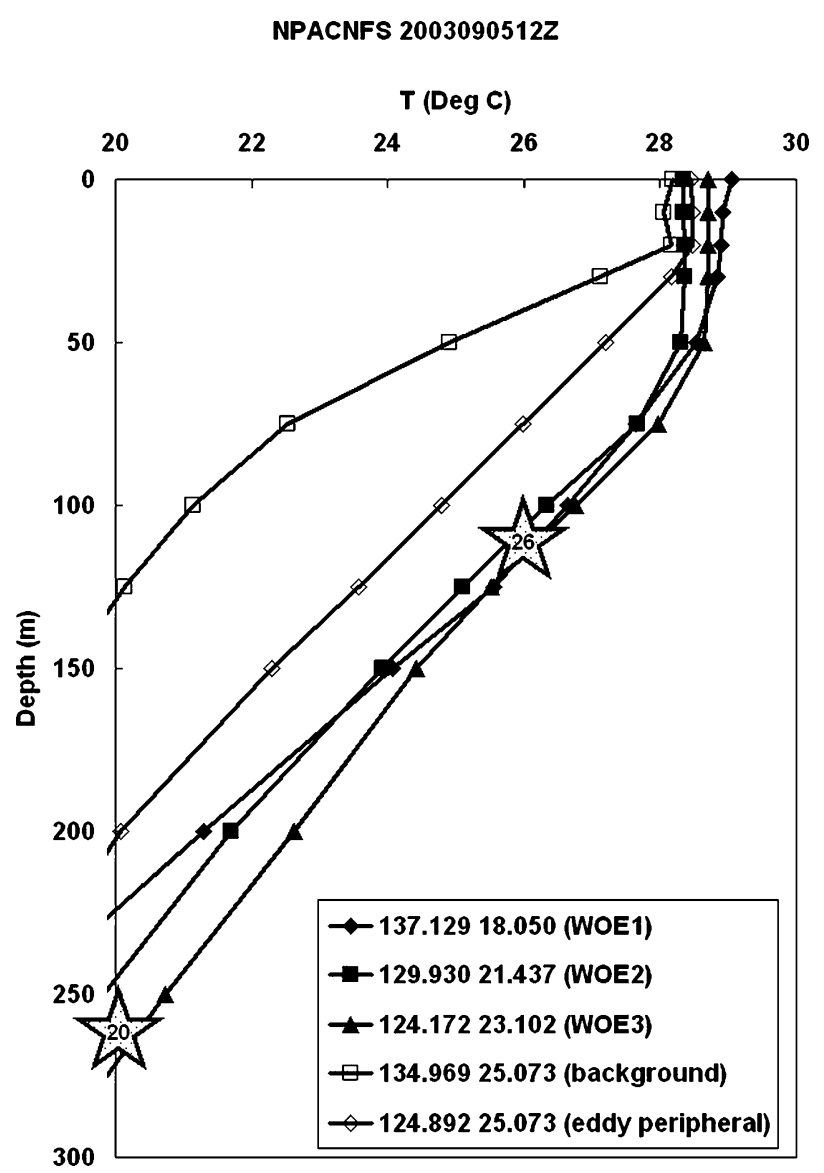

FIG. 3. Vertical temperature profiles from the NRL's NPACNFS model output showing the three warm eddy regions (WOE-1: solid diamond; WOE-2: solid square; WOE-3: solid triangle), eddy peripheral (blank diamond), and the reference/background (blank square). The SSHA-estimated depths of $20^{\circ}$ and $26^{\circ} \mathrm{C}$ using Shay et al.'s (2000) algorithm are annotated as large stars.

sity increase of $22 \mathrm{~m} \mathrm{~s}^{-1}$ within $24 \mathrm{~h}$ is well above the criteria of rapid intensification (increase in maximum sustained surface wind speed of $15.4 \mathrm{~m} \mathrm{~s}^{-1}$ within $24 \mathrm{~h}$ ) as defined by Kaplan and DeMaria (2003). The peak intensity of $77 \mathrm{~m} \mathrm{~s}^{-1}$, slightly stronger than Maemi's counterpart, Hurricane Isabel in the Atlantic, made Maemi the most intense tropical cyclone in 2003.

After passing the core of WOE-2 (0000 UTC 10 September) and moving over the periphery of WOE-2 and WOE-3, Maemi's intensity started to decline gradually, but still maintained category-5/upper-category-4 intensity for another $36 \mathrm{~h}$, until 1200 UTC 11 September (Figs. 4 and 5). From 1200 UTC 11 September, Maemi moved into the East China Sea (P5) and weakened considerably. At 0600 UTC 12 September, Maemi, with an intensity of $51 \mathrm{~m} \mathrm{~s}^{-1}$ (category 3 ), struck the southern Korean peninsula, killing 70 and causing serious damage. 


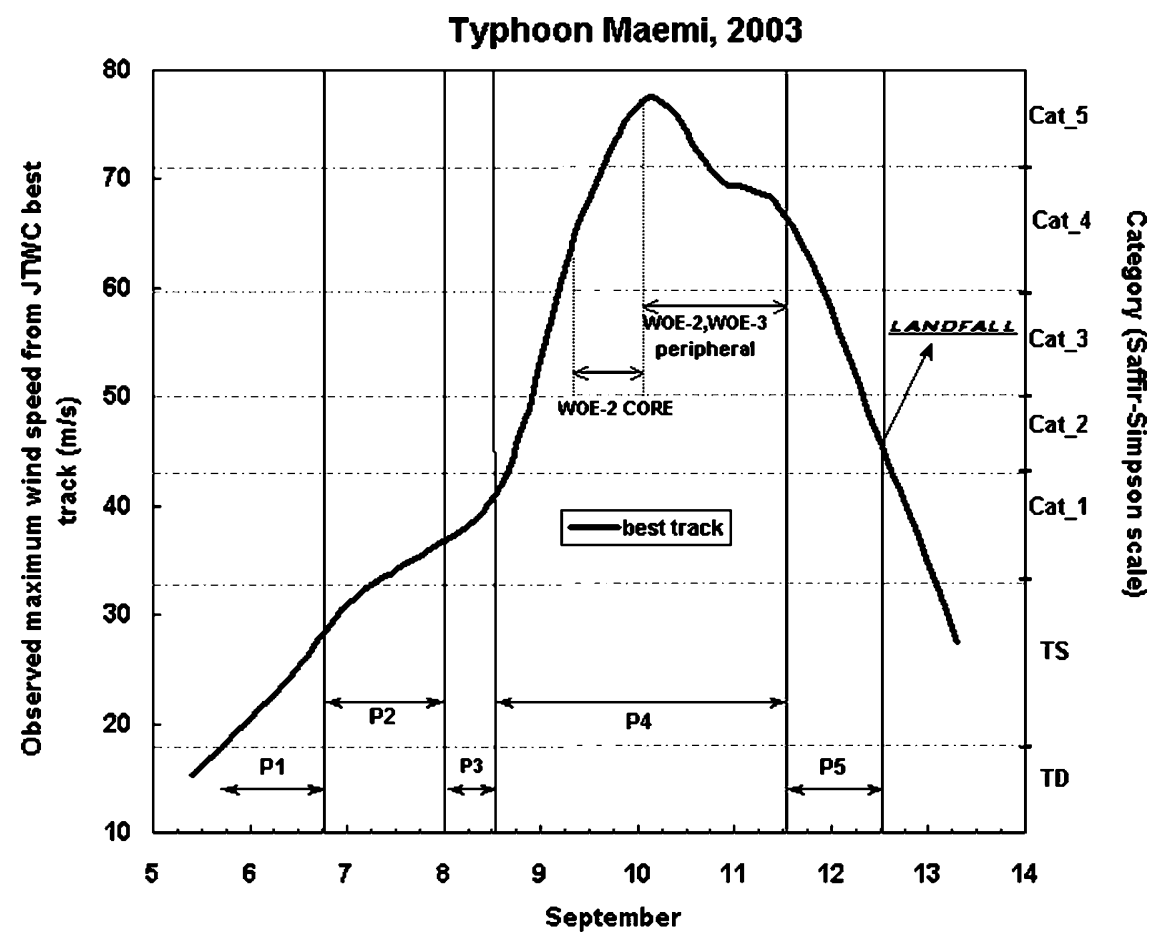

FIG. 4. The observed intensity evolution of Maemi from JTWC's best-track data. The five periods, defined according to different ocean regions that Maemi passed over, are illustrated together with the Saffir-Simpson scales (right axis).

\section{Results of a CHIPS hindcast}

Using the CHIPS model (Emanuel 1999; Emanuel et al. 2004), numerical experiments were conducted to assess the influence of the warm eddies on the intensification of Maemi. CHIPS is a simple coupled atmosphere-ocean model. Its axisymmetric atmospheric component (Emanuel 1995) is coupled to a one-dimensional ocean model developed by Schade (1997). The CHIPS ocean component assumes a very simple upperocean thermal structure with an assumed mixed layer of variable depth and constant thermal stratification below the mixed layer. Both the mixed-layer depth and submixed-layer thermal stratification are specified as a function of space and time using monthly mean climatology. In the coupling, it is assumed that typhoon intensity responds primarily to sea surface temperature change under the eyewall, and this sea surface temperature change can be approximated by the sea surface temperature change under that part of the eyewall that lies along the typhoon track (Emanuel et al. 2004). This assumption is supported by the recent comprehensive observational analyses by Cione and Uhlhorn (2003) that the inner-core sea surface temperature anomaly is a key parameter influencing tropical cyclone intensity. Meanwhile, a parameterization of the vertical wind shear ${ }^{1}$ is included to account for the ventilation of low-entropy air through the cyclone center at midlevels (Emanuel et al. 2004). Although CHIPS is a simple model, its hindcast experiments provide some first-order physical insights into the currently not-well-explored issue of tropical cyclone-eddy interaction.

Numerical experiments are run with and without the eddy information derived from the satellite SSHA field. The run without the eddy input uses monthly climatological ocean mixed-layer depth (Levitus 1982). The one with the eddy input uses one cycle (10 days) of the observed pretyphoon satellite $\mathrm{SSHA}^{2}$ measurement as input into an algorithm developed by Shay et al. (2000) to estimate a new mixed-layer depth (Emanuel et al. 2004). To test the validity of Shay et al.'s algorithm, the

\footnotetext{
${ }^{1}$ The CHIPS hindcast used vertical wind shear values from the gridded analyses of the NCEP Global Forecast System. The velocities at 250 and $850 \mathrm{hPa}$ were smoothed over a large area surrounding the storm to estimate the shear.

${ }^{2}$ Note that the near-real time (available $3 \mathrm{~h}$ from measurements) SSHA product from the Jet Propulsion Laboratory is used here. We have done the comparison and shown that the quality of this SSHA is comparable to the high-accuracy 1-month-delayed Geophysical Data Records (GDR) product.
} 


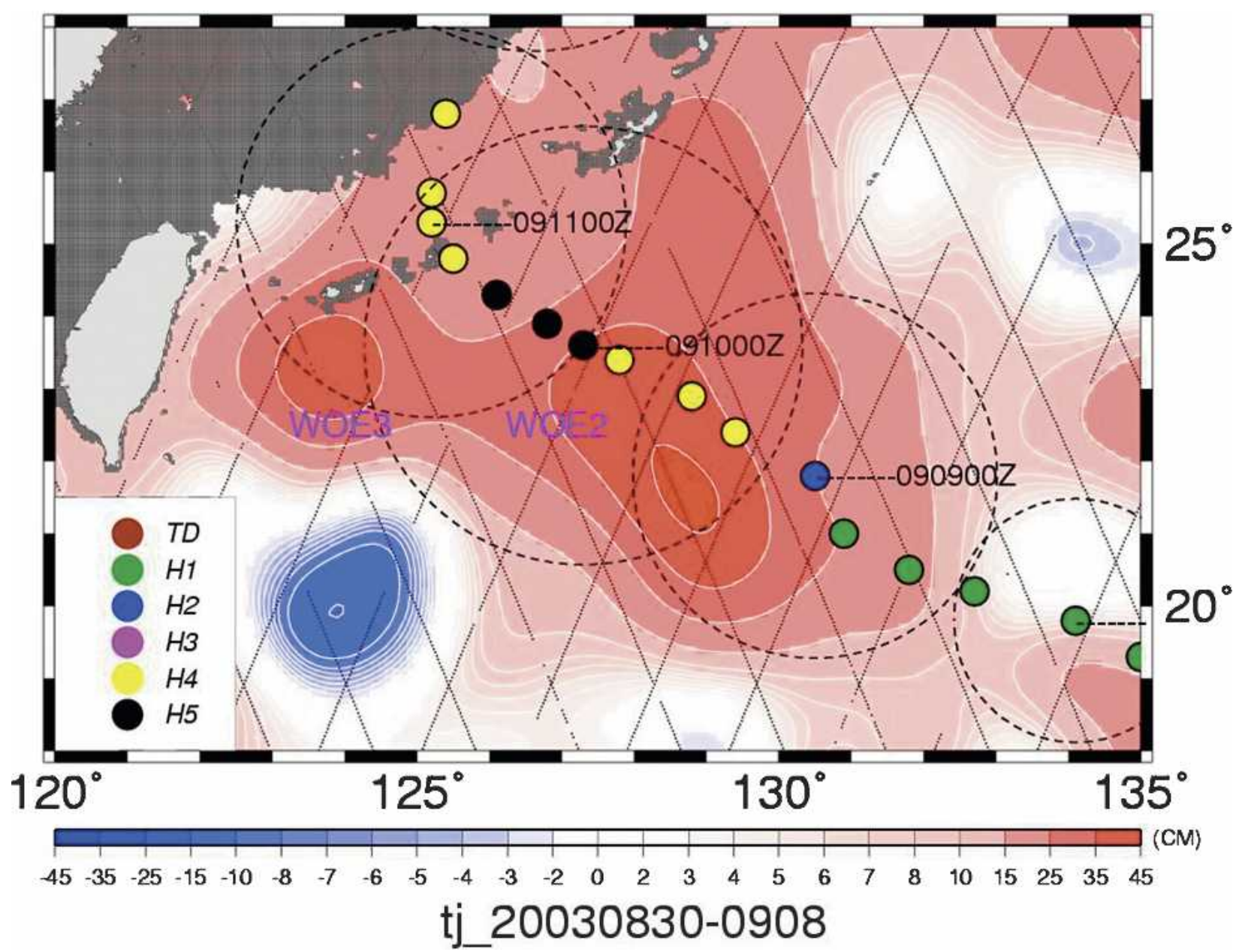

FIG. 5. Detailed SSHA distribution from a composite of TOPEX/Poseidon and Jason-1 measurements during the cycle (30 Aug-8 Sep) before Maemi's encounter of WOE-2. Maemi's intensity (in Saffir-Simpson scale) and radius of maximum wind are also shown. The storm position is denoted every $6 \mathrm{~h}$.

estimated depths of $20^{\circ}$ and $26^{\circ} \mathrm{C}$ in the WOE- 2 are plotted (indicated with the asterisk in Fig. 3) along with the NPACNFS profiles (Fig. 3). As shown in Fig. 3, the estimated $20^{\circ}$ and $26^{\circ} \mathrm{C}$ depth is about 260 and $120 \mathrm{~m}$, which is in good agreement with the $20^{\circ}$ and $26^{\circ} \mathrm{C}$ depth of NPACNFS in the WOE- 2 core.

Figure 6 illustrates results from an 8-day intensity hindcast experiment using CHIPS. Four experiments were run: 1) a control experiment using weekly NCEP sea surface temperature data and the monthly climatological mixed-layer depth (denoted as CTRL); 2) an experiment using SSHA to adjust the mixed-layer depth (denoted as EDDY); 3) an experiment with the sea surface temperature corrected to include the cold wake previously induced by Typhoon Dujuan along the track of Maemi (denoted as WAKE); and 4) an experiment with both the cold wake and the warm eddy (denoted as WK-ED). The JTWC's best-track data are plotted as OBS in Fig. 6a. All the runs were initialized by matching to the best-track intensity data for the first $24 \mathrm{~h}$.

In Fig. 6a it is evident that the intensity evolutions from the two runs including the eddy-adjusted mixedlayer depth (EDDY; WK-ED) are much closer to the observations than the other two runs without the eddy (CTRL; WAKE), which have greater errors in both the magnitude and timing of the peak intensity, while the intensity also weakens significantly after its peak is reached. The peak intensity is 68 and $67 \mathrm{~m} \mathrm{~s}^{-1}$ for both runs without the eddy (CTRL and WAKE, respectively), but the observed peak is $77 \mathrm{~m} \mathrm{~s}^{-1}$, occurring at 0300 UTC 10 September (Fig. 6a). Maemi reaches its maximum intensity in CTRL/WAKE at 1800 UTC 9 September, $9 \mathrm{~h}$ earlier than observed. In addition, once reaching its peak, the intensity of both CTRL and WAKE weakens immediately. The intensity at 1800 

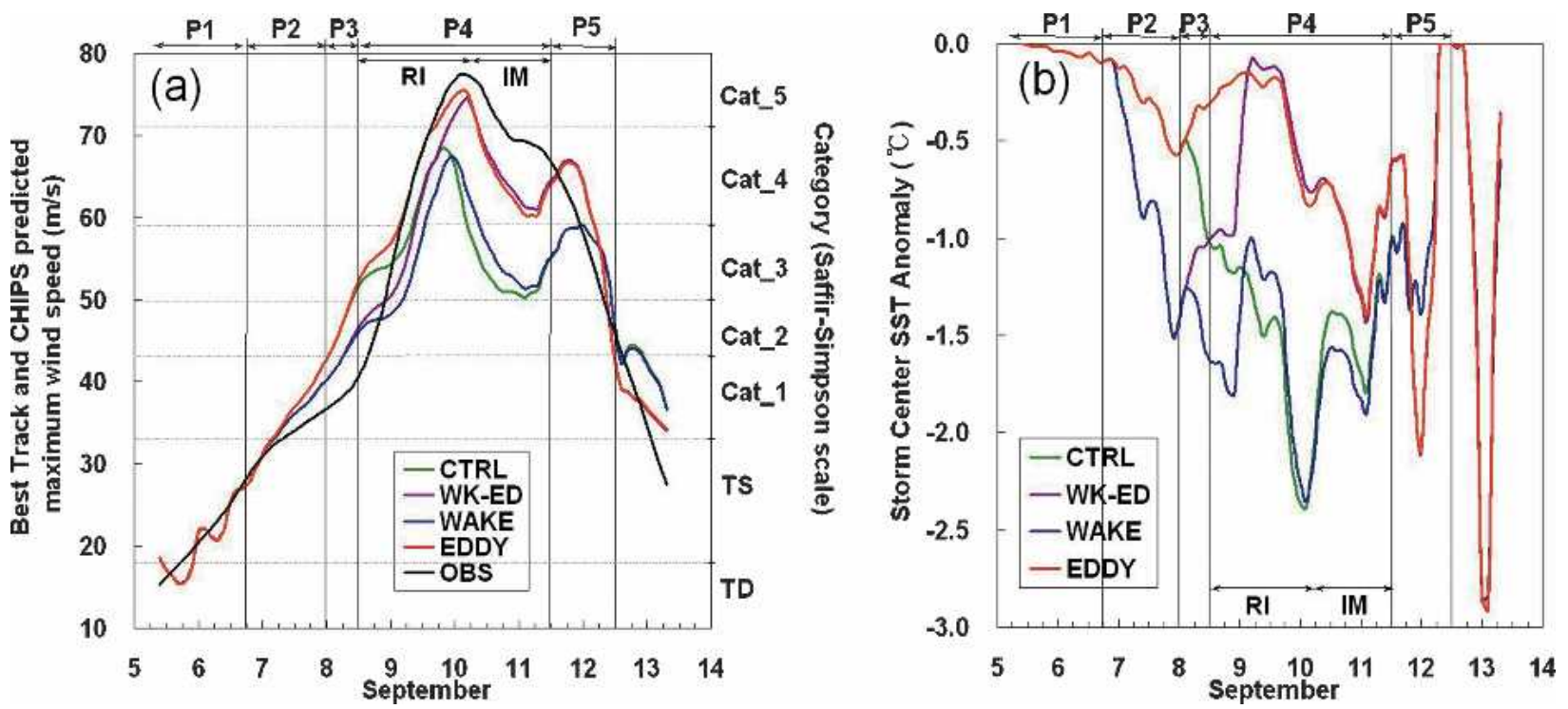

FIG. 6. Results of four different runs of CHIPS (CTRL: a controlled run using standard CHIPS input; EDDY: run with the SSHA data; WAKE: run with Dujuan's cold wake data; and WK-ED: run with both the SSHA and Dujuan's cold wake data) shown together with observations (OBS). (a) The intensity $\left(\mathrm{m} \mathrm{s}^{-1}\right.$ ) evolution, where the period of the rapid intensification is denoted as RI, and the period of intensity maintenance is denoted as IM. (b) The typhoon-induced sea surface temperature anomaly at the storm center.

UTC 10 September declines to near $51 \mathrm{~m} \mathrm{~s}^{-1}$ (for CTRL) and $53 \mathrm{~m} \mathrm{~s}^{-1}$ (for WAKE), while the observed intensity is still at $69 \mathrm{~m} \mathrm{~s}^{-1}$ (Fig. 6a). When the warm eddy is included to initialize a deeper mixed layer in CHIPS, an improvement in intensity hindcast is evident. The peak intensity for both EDDY and WK-ED reaches $75 \mathrm{~m} \mathrm{~s}^{-1}$, in good agreement with the observed best-track intensity peak. The timing of peak intensity is also well captured (Fig. 6a). More importantly, the intensity is better sustained in both runs with the eddy information. For example, at 1800 UTC 10 September, the observed intensity is $69 \mathrm{~m} \mathrm{~s}^{-1}$ and the two runs including the eddy (EDDY and WK-ED) also maintain the storm at $65 \mathrm{~m} \mathrm{~s}^{-1}$, in contrast to the $51 / 53 \mathrm{~m} \mathrm{~s}^{-1}$ of the two runs without the eddy (CTRL and WAKE) (Fig. 6a).

The aforementioned results are further substantiated by analyzing the time evolution of the sea surface temperature perturbation (Fig. 6b), the undisturbed mixedlayer depth, and the model-predicted mixed-layer depth at the storm center (Figs. 7a,b). Figure 6b shows the time series of the Maemi-induced sea surface temperature anomaly at the storm center for the four model runs (CTRL; EDDY; WAKE; WK-ED). Comparison of the observed and simulated evolutions of the sea surface temperature anomaly (Fig. 6b) and the storm intensity (Fig. 6a) shows good agreement. Specifically, during the $\mathrm{P} 4$ period, the sea surface temperature of both eddy runs (WK-ED and EDDY) shows little cooling at the storm center (sea surface tempera- ture anomaly $\leq 1.0^{\circ} \mathrm{C}$ ) (Fig. 6b). During Maemi’s rapid intensification, as it traveled over the core of WOE-2 (1200 UTC 9 September) (Figs. 5 and 6a), the sea surface cooling (WK-ED and EDDY) is as little as $0.5^{\circ} \mathrm{C}$ (Fig. 6b). It is evident that the thick layer of warm water associated with the eddy (Fig. 3) significantly reduces the storm-induced sea surface cooling. Because this important negative feedback (Gallacher et al. 1989; Bender and Ginis 2000) is limited, intensification is correspondingly greater. In the two runs without the eddy (CTRL and WAKE), the sea surface cooling is overestimated (sea surface temperature anomaly between $1.5^{\circ}$ and $2.5^{\circ} \mathrm{C}$; Fig. $6 \mathrm{~b}$ ), resulting in a sharp intensity drop, and therefore the intensity cannot be boosted or sustained (Fig. 6a). The above finding is consistent with the investigation of Hurricane Opal-eddy interaction by Hong et al. (2000), and with Shay et al. (2000)'s finding that the sea surface cooled by approximately $0.5^{\circ} \mathrm{C}$ when Opal passed the center of the Loop Current warm core ring, during which it intensified rapidly. It is also consistent with the statistical finding of Cione and Uhlhorn (2003) that intensification is observed when the sea surface cooling is $\leq 1.0^{\circ} \mathrm{C}$.

The role of the eddy in the different sea surface temperature changes in Fig. $6 \mathrm{~b}$ can also be depicted by the evolution of the mixed-layer depth in CHIPS. When the eddy is included, the prestorm mixed-layer depth is much larger closer to the center of WOE-2 (see Fig. 7a). Without the eddy, the undisturbed mixed-layer depth remains less than $50 \mathrm{~m}$, while at the core of the 

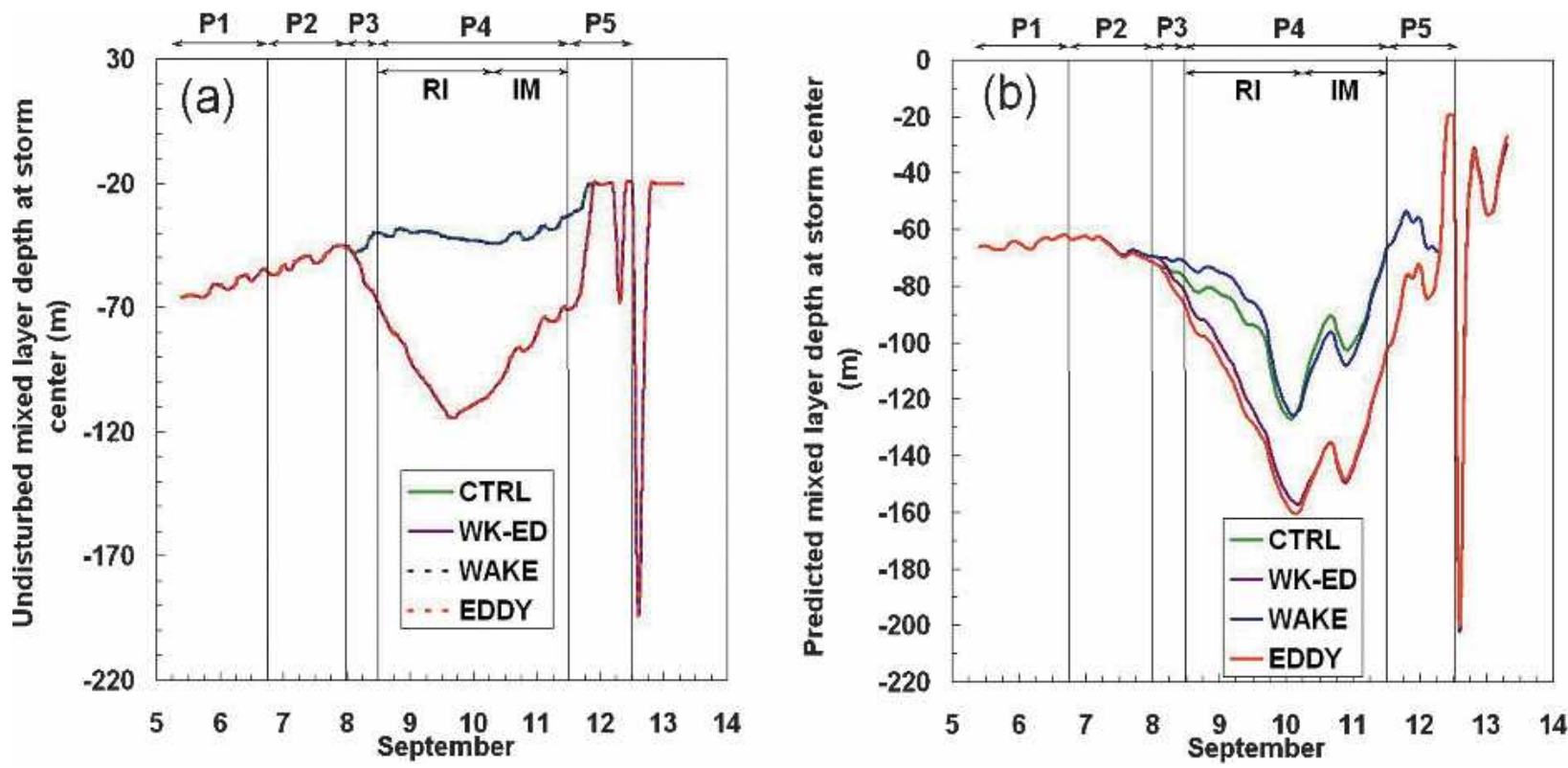

FIG. 7. Same as Fig. 6, but showing (a) the undisturbed mixed-layer depth at the storm center, and (b) the predicted mixed-layer depth.

eddy, it approaches $115 \mathrm{~m}$ (Fig. 7a). As such, with the shallower undisturbed mixed-layer depth in the run without the warm eddy, much stronger entrainment mixing is induced (the predicted mixed-layer depth deepens from 45 to about 120 m; see Fig. 7b), and this leads to more sea surface cooling at the storm center (Fig. 6b). On the contrary, when the eddy is considered in both EDDY and WK-ED, with a deeper undisturbed mixed layer (Fig. 7a), weaker entrainment occurs and the predicted mixed layer only deepens from 115 to about $160 \mathrm{~m}$ (Fig. 7b). In other words, the presence of the deeper mixed layer associated with the warm eddy and the weaker entrainment response makes the Maemi-induced sea surface cooling at the storm center much smaller (Fig. 7b). As Maemi continued to intensify while moving out of the core of WOE-2 (Figs. 1, 5, and $6 \mathrm{~b}$ ) from 0000 UTC 10 September, sea surface cooling increases with the increase in wind speed over the region of shallower (Figs. 3 and 6b) warm water (Price 1981).

Figure 8a denotes the TMI and AMSR-E observations of the poststorm sea surface cooling by subtracting the sea surface temperature observation on 8 September (i.e., before Maemi entering WOE-2) from the sea surface temperature observation on 12 September (36-48 $\mathrm{h}$ after Maemi leaving WOE-2). In Fig. 8a, it is clear that in the core of WOE-2, the sea surface cooling is small $\left(\leq 1.2^{\circ} \mathrm{C}\right.$, in green) as compared with the large sea surface temperature reduction $\left(2.5^{\circ}-4.5^{\circ} \mathrm{C}\right.$, in purple-black) outside the eddy region. Note that the poststorm sea surface cooling (Fig. 8a) is generally much larger than the sea surface cooling that takes place directly under the storm core (Fig. 6b). As revealed by the statistical analysis of 23 Atlantic hurricanes undertaken by Cione and Uhlhorn (2003), the sea surface cooling under the storm core is about $5 \%-30 \%$ of the poststorm cooling.

In addition to these findings on the role of the warm eddy in the storm's intensity, we address the separate issue of the influence of the cold wake induced by the previous typhoon (Dujuan). As shown in Fig. 6a, inclusion of the cold wake induced by Dujuan further improves the intensity forecast. As can be seen, the intensity is overestimated during the $\mathrm{P} 3$ period in the two runs without the Dujuan-induced cold wakes (CTRL and EDDY, which use the NCEP weekly sea surface temperature field that does not include Dujuan's wake). In both CTRL and EDDY, the intensity at 1200 UTC 8 September is $52 \mathrm{~m} \mathrm{~s}^{-1}$, an overestimation of 12 $\mathrm{m} \mathrm{s}^{-1}$ over the best-track intensity of $40 \mathrm{~m} \mathrm{~s}^{-1}$. When Dujuan's cold wake information is incorporated into the two runs with the cold wake information (WAKE and WK-ED, based on the TMI and AMSR-E sea surface temperature measurements), the corresponding intensity is $46 \mathrm{~m} \mathrm{~s}^{-1}$ and the overestimation error is reduced to $6 \mathrm{~m} \mathrm{~s}^{-1}$ (Fig. 6a). The difference in Dujuan's wake region between the NCEP weekly sea surface temperature and the TMI/AMSR-E sea surface temperature is illustrated in Fig. 8b. It can be seen that during the P3 period (0000-1200 UTC 8 September), 

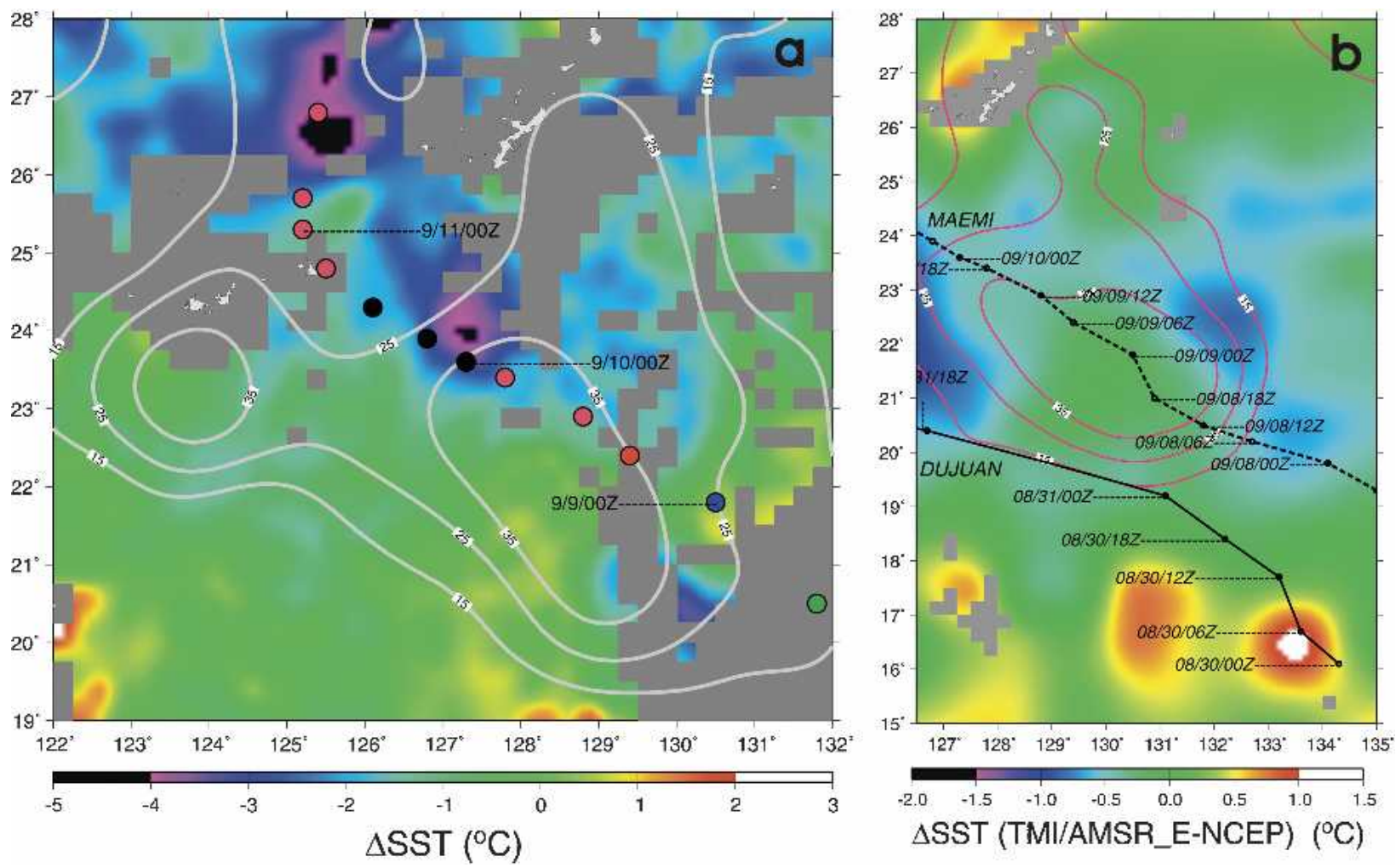

FIG. 8. (a) TMI and AMSR-E observed poststorm sea surface temperature cooling (sea surface temperature difference between 12 and $8 \mathrm{Sep}$ ) associated with the passage of Maemi. (b) Difference between the TMI/AMSR-E sea surface temperature observation (2-4 Sep) and the NCEP weekly sea surface temperature (29 Aug-4 Sep), indicating the Dujuan-induced cold sea surface temperature wake.

the sea surface temperature difference along Maemi's track is around $1^{\circ} \mathrm{C}$. The sea surface temperature difference during the P4 period (1200 UTC 8 September to 0000 UTC 10 September) is minimal as it is in the WOE-2 region, typically in the range of $0.3^{\circ}$ to $0^{\circ} \mathrm{C}$ (in green; Fig. 8b).

Note that a secondary intensification is shown during the P5 period (1200 UTC 11 September-1200 UTC 12 September) in all the model runs (Fig. 6a). The peak of this secondary intensification appears at 0000 UTC 12 September, $12 \mathrm{~h}$ before Maemi's landfall. This is possibly due to the shoaling effect just prior to landfall as described in Emanuel et al. (2004). As a typhoon approaches land, the seafloor shoals gradually along the typhoon track and rises to meet the mixed-layer base. Thus there is no cold water to be mixed with the surface and the ocean cooling stops (Emanuel et al. 2004).

\section{Discussion}

\section{a. Role of the warm ocean eddy in tropical cyclone rapid intensification}

To our knowledge, three other tropical cyclonewarm oceanic feature interaction cases (Hurricanes
Opal, Mitch, and Bret) have been studied using atmosphere-ocean coupled models (Hong et al. 2000; Emanuel et al. 2004). All these cases are hurricanes in the Gulf of Mexico. Opal (1995) was simulated in Hong et al. (2000) using the U.S. Naval Research Laboratory's Coupled Ocean-Atmosphere Mesoscale Prediction System (COAMPS) as the atmospheric component and the Geophysical Fluid Dynamics Laboratory's (GFDL) Modular Ocean Model Version 2 (MOM2) as the oceanic component (Fig. 9a). The other two cases, Mitch (1998) and Bret (1999), were run using the CHIPS model (Emanuel et al. 2004; Figs. 9b,c). In all four cases, rapid intensification is observed. ${ }^{3}$ The major characteristics of the rapid intensification are summarized in Table 1. From Figs. 6a and 9, it is clear that the tropical cyclone intensity is underestimated in all cases without the warm ocean eddy information. With additional eddy information in the numerical experiments, the predicted intensity is evidently improved compared

\footnotetext{
${ }^{3}$ As Opal was hindcasted in minimum sea level pressure (Hong et al. 2000), the rapid intensification period of Opal in Fig. 9a is defined according to the observed maximum sustained surface wind speed as reported in Shay et al. (2000).
} 

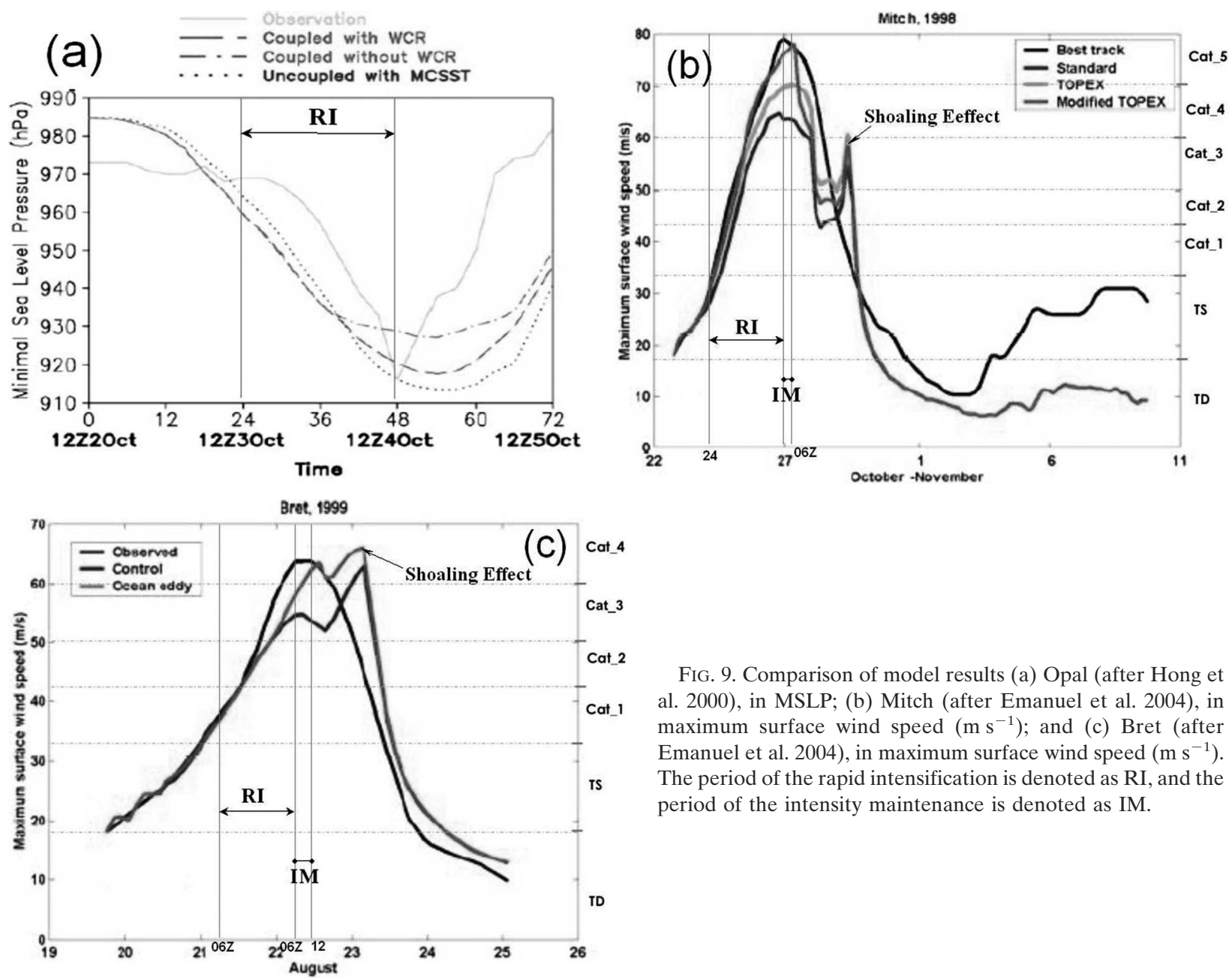

FIG. 9. Comparison of model results (a) Opal (after Hong et al. 2000), in MSLP; (b) Mitch (after Emanuel et al. 2004), in maximum surface wind speed $\left(\mathrm{m} \mathrm{s}^{-1}\right)$; and (c) Bret (after Emanuel et al. 2004), in maximum surface wind speed $\left(\mathrm{m} \mathrm{s}^{-1}\right)$. The period of the rapid intensification is denoted as RI, and the period of the intensity maintenance is denoted as IM.

to observations. In the case of Opal, the peak of simulation without the eddy (green curve) is $928 \mathrm{hPa}$ (Fig. 9a). When the eddy is included (red curve), the peak intensity reaches $918 \mathrm{hPa}$, which is in good agreement with the observed peak value of $917 \mathrm{hPa}$ (Hong et al. 2000), though the timing of the peak was off by about $12 \mathrm{~h}$. In the case of Mitch, the observed peak intensity is $79 \mathrm{~m} \mathrm{~s}^{-1}$ (black curve) and the peak intensities of the simulations with the eddy (red curve) and the without the eddy (blue curve) are 78 and $64 \mathrm{~m} \mathrm{~s}^{-1}$, respectively (Fig. 9b), while the timing of the peak is well captured. In the case of Bret, the observed peak intensity is 63 $\mathrm{m} \mathrm{s}^{-1}$ (black curve), while the peak intensities of the runs with TOPEX (red curve, ocean eddy) and without (blue curve, control) are 63 and $53 \mathrm{~m} \mathrm{~s}^{-1}$, respectively (Fig. 9c), while the timing of the peak is off by about $6 \mathrm{~h}$.

It is clear that incorporating eddy information helps improve the peak intensity prediction, especially around the time of peak intensity. Nevertheless, warm eddies may not be the sole factor in rapid intensifica- tion, since it can be seen that even in the simulations without eddies (CTRL and WAKE curves in Fig. 6a; green curve in Fig. 9a; blue curves in Figs. 9b and 9c), rapid intensification still takes place, though the intensity does not peak as high as that in the simulations with eddies (EDDY and WK-ED curves in Fig. 6a; coupled with WCR curve in Fig. 9a; red curves in Figs. 9b and $9 c)$. For the case of Maemi, this is perhaps because the $850-250-\mathrm{hPa}$ vertical wind shear at the storm center is small ( $\sim 5 \mathrm{~m} \mathrm{~s}^{-1}$; figure not shown) and the maximum potential intensity (not shown) is large during the rapid intensification period (from 1200 UTC 9 September to 0000 UTC 10 September). The rate of intensification of Maemi (in maximum surface wind speed) is underestimated by just $5 \%$ in the simulation with the eddy, while in the run without the eddy, the intensification rate in underestimated by $26 \%$ (Table 1 ).

In the case of Opal (Fig. 9a; Hong et al. 2000), a favorable atmospheric upper-level trough interaction may have taken place during rapid intensification 
TABLE 1. Comparison of the rapid intensification parameters based on coupled model results for Maemi (2003), Opal (1995), Bret (1999), and Mitch (1998).

\begin{tabular}{|c|c|c|c|c|}
\hline & Maemi (this work) & $\begin{array}{l}\text { Opal } \\
\text { (Shay et al. 2000; } \\
\text { Hong et al. 2000) }\end{array}$ & $\begin{array}{c}\text { Bret } \\
\text { (Goni and } \\
\text { Trinanes 2003; } \\
\text { Emanuel et al. 2004) }\end{array}$ & $\begin{array}{c}\text { Mitch } \\
\text { (Goni and } \\
\text { Trinanes 2003; } \\
\text { Emanuel et al. 2004) }\end{array}$ \\
\hline Location & Western North Pacific & Gulf of Mexico & Gulf of Mexico & Gulf of Mexico \\
\hline RI period & $\begin{array}{l}0600 \text { UTC } 8 \text { Sep-0600 } \\
\text { UTC } 10 \text { Sep } 2003\end{array}$ & $\begin{array}{l}1200 \text { UTC } 3 \text { Oct }-1200 \\
\text { UTC } 4 \text { Oct } 1995\end{array}$ & $\begin{array}{l}0600 \text { UTC } 21 \text { Aug-0600 } \\
\text { UTC } 22 \text { Aug } 1999\end{array}$ & $\begin{array}{l}0000 \text { UTC } 24 \text { Oct-0000 } \\
\text { UTC } 27 \text { Oct } 1998\end{array}$ \\
\hline RI duration (h) & $48 \mathrm{~h}$ & $24 \mathrm{~h}$ & $24 \mathrm{~h}$ & $72 \mathrm{~h}$ \\
\hline Observed peak (best track) & $77 \mathrm{~m} \mathrm{~s}^{-1}$ (category 5) & $916 \mathrm{hPa}$ (category 5) & $64 \mathrm{~m} \mathrm{~s}^{-1}$ (category 4$)$ & $79 \mathrm{~m} \mathrm{~s}^{-1}$ (category 5 ) \\
\hline $\begin{array}{l}\text { Observed intensity at the } \\
\text { beginning of RI }\end{array}$ & $38 \mathrm{~m} \mathrm{~s}^{-1}$ (category 1 ) & $969 \mathrm{hPa}$ (category 2) & $38 \mathrm{~m} \mathrm{~s}^{-1}$ (category 1 ) & $\begin{array}{l}27 \mathrm{~m} \mathrm{~s}^{-1} \text { (tropical } \\
\text { storm) }\end{array}$ \\
\hline Intensity increase during RI & $77-38=39 \mathrm{~m} \mathrm{~s}^{-1}$ & $916-969=-53 \mathrm{hPa}$ & $64-38=26 \mathrm{~m} \mathrm{~s}^{-1}$ & $79-27=52 \mathrm{~m} \mathrm{~s}^{-1}$ \\
\hline Coupled model used & CHIPS & COAMPS-MOM2 & CHIPS & CHIPS \\
\hline $\begin{array}{l}\text { Model-estimated peak from } \\
\text { the simulation with the } \\
\text { warm eddy }\end{array}$ & $75 \mathrm{~m} \mathrm{~s}^{-1}$ (category 5) & $917 \mathrm{hPa}$ (category 5) & $64 \mathrm{~m} \mathrm{~s}^{-1}$ (category 4) & $78 \mathrm{~m} \mathrm{~s}^{-1}$ (category 5) \\
\hline $\begin{array}{l}\text { Peak underestimation and } \\
\text { underestimation } \\
\text { percentage in RI from } \\
\text { the simulation with the } \\
\text { warm eddy }\end{array}$ & $\begin{array}{l}77-75=2 \mathrm{~m} \mathrm{~s}^{-1} \\
2 / 39=5 \%\end{array}$ & $\begin{array}{l}916-9171 \mathrm{hPa}=-1 \mathrm{hPa} \\
(-1) /(-53)=2 \%\end{array}$ & $\begin{array}{l}64-64=0 \\
0 / 26=0 \%\end{array}$ & $\begin{array}{l}79-78=1 \mathrm{~m} \mathrm{~s}^{-1} \\
1 / 52=2 \%\end{array}$ \\
\hline $\begin{array}{l}\text { Model-estimated peak from } \\
\text { the simulation without } \\
\text { the warm eddy }\end{array}$ & $67 \mathrm{~m} \mathrm{~s}^{-1}$ (category 4 ) & $932 \mathrm{hPa}$ (category 4) & $56 \mathrm{~m} \mathrm{~s}^{-1}$ (category 3 ) & $65 \mathrm{~m} \mathrm{~s}^{-1}$ (category 4$)$ \\
\hline $\begin{array}{l}\text { Peak underestimation and } \\
\text { underestimation } \\
\text { percentage in RI from } \\
\text { the simulation without } \\
\text { the warm eddy }\end{array}$ & $\begin{array}{l}77-67=10 \mathrm{~m} \mathrm{~s}^{-1} \\
10 / 39=26 \%\end{array}$ & $\begin{array}{l}916-9321 \mathrm{hPa}=-16 \mathrm{hPa} \\
(-16) /(-53)=30 \%\end{array}$ & $\begin{array}{l}64-56=8 \mathrm{~m} \mathrm{~s}^{-1} \\
8 / 26=31 \%\end{array}$ & $\begin{array}{l}79-65=14 \mathrm{~m} \mathrm{~s}^{-1} \\
14 / 52=27 \%\end{array}$ \\
\hline
\end{tabular}

(Bosart et al. 2000; Shay et al. 2000). Similar to the Maemi results, the rate of intensification of Opal [in minimum sea level pressure (MSLP)] is underestimated by just $2 \%$ in the simulation with the eddy, while in the run without the eddy, the intensification rate in underestimated by $30 \%$ (Table 1 ).

Similar results are found in both cases of Mitch and Bret. In Mitch (Emanuel et al. 2004; Fig. 9b), the rapid intensification in the simulation with the eddy is underestimated by $2 \%$ while in the run without the eddy, the rate is underestimated by $27 \%$ (Table 1 ). In the case of Bret (Emanuel et al. 2004; Fig. 9c), the peak intensity in the simulation with the eddy is the same as the observed peak of $64 \mathrm{~m} \mathrm{~s}^{-1}$, while in the run without the eddy, the peak is underestimated by $8 \mathrm{~m} \mathrm{~s}^{-1}$ (i.e., the modeled peak of $56 \mathrm{~m} \mathrm{~s}^{-1}$ subtracted from the observed peak of $64 \mathrm{~m} \mathrm{~s}^{-1}$ ), accounting for a $31 \%$ underestimation in the total observed rapid intensification amount of $26 \mathrm{~m} \mathrm{~s}^{-1}$ (Table 1).

In all four cases we found that even without the incorporation of the warm eddy information in the numerical experiments, rapid intensification still takes place, though the peak intensity is underestimated. With the addition of the warm eddies in the numerical experiments, the peak intensity is better captured in all cases and the percentage underestimation of intensity during the rapid intensification period is typically $\leq 5 \%$, in contrast to the $26 \%-30 \%$ underestimation in the runs without the eddies (Table 1). The above results suggest that the primary effect of warm eddies or other oceanic features is to increase the peak intensity, typically by one category.

\section{b. Role of warm-ocean eddies in tropical cyclone intensity maintenance}

From the best-track observations shown in Figs. 4 and 5, it can be seen that Maemi's intensity was sustained at category 4 and above during the $36 \mathrm{~h}$ from 0000 UTC 10 September to 1200 UTC 11 September, when Maemi moved from the WOE-2 core to the periphery of WOE-2 and WOE-3 (SSHA $\sim 15 \mathrm{~cm}$; Fig. 5). The CHIPS hindcast results discussed in section 4 suggest that the warm eddy helps sustain Maemi's intensity during this 36-h period. In the case of Opal, it can be seen in Fig. 10a that soon after reaching its peak intensity at 1200 UTC 4 October (Fig. 10b), Opal moved out of the region of the warm eddy, after which its intensity was not sustained (yellow curve in Fig. 9a). 

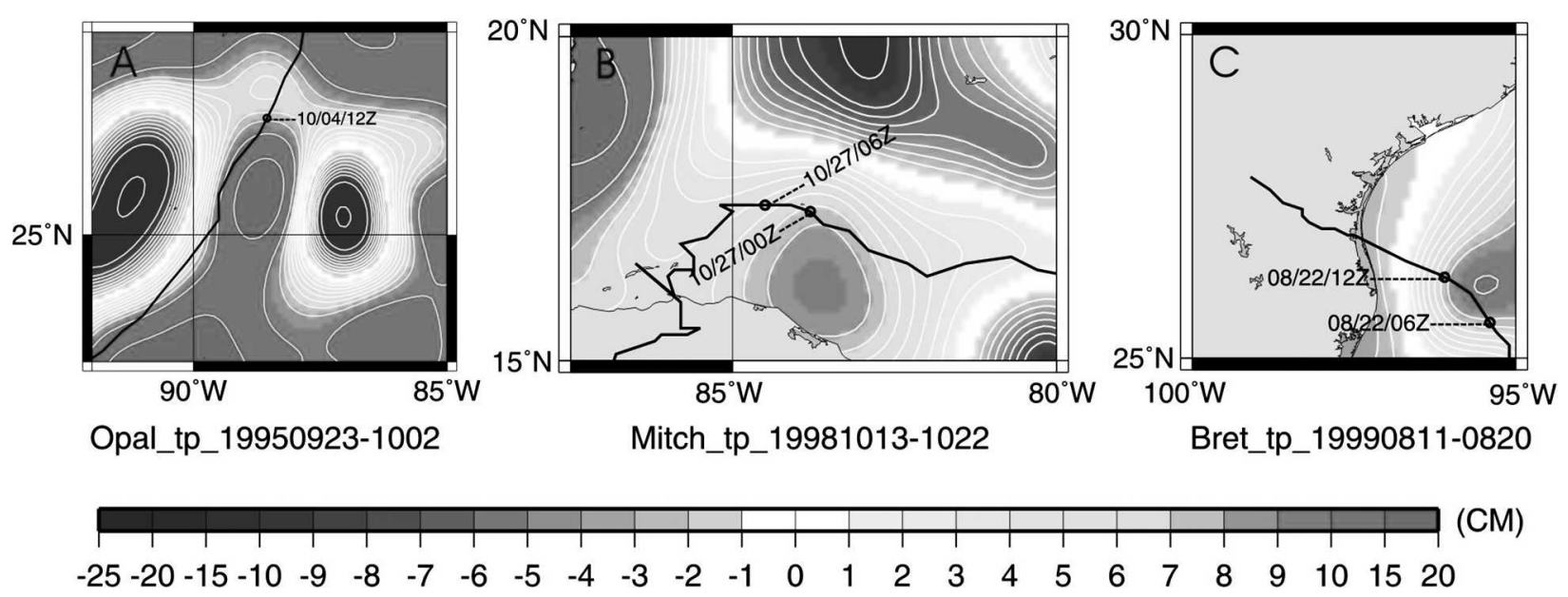

FIG. 10. Prestorm SSHA maps for (a) Opal, (b) Mitch, and (c) Bret cases with tracks overlaid.

In contrast, Bret did not move out of the warm eddy region (SSHA $\sim 7 \mathrm{~cm}$ ) until 1200 UTC 22 August 1999; Fig. 10b), $6 \mathrm{~h}$ after reaching its peak intensity (0600 UTC 22 August 1999); during this short period, Bret's intensity was sustained (black curve in Fig. 9c). Soon after, as Bret moved into coastal waters, the shoaling effect (Emanuel et al. 2004) is observed (red and blue curves in Fig. 9c). Mitch is similar to Bret, maintaining its intensity for $6 \mathrm{~h}$ after reaching its peak as it moved out of the warm eddy region and made landfall (Figs. 9b and 10b). These results support the idea that warm eddies help maintain tropical cyclone intensity.

\section{Conclusions}

This study presents an investigation of the interaction between Supertyphoon Maemi and warm ocean eddies, using JTWC's best-track data, multiple remote sensing datasets, NRL/NPACNFS upper-ocean thermal profiles, and the CHIPS coupled typhoon-ocean model. In early September 2003, Maemi passed over the southern $\left(\sim 22^{\circ} \mathrm{N}\right)$ eddy zone in the western North Pacific and encountered three prominent warm-ocean eddies. The best-track data together with satellite observations of sea surface height from TOPEX/Poseidon and Jason-1 indicate that within $36 \mathrm{~h}$ (1200 UTC 8 September to 0000 UTC 10 September) of encountering warm eddy WOE-2, Maemi's intensity escalated rapidly from 41 $\mathrm{m} \mathrm{s}^{-1}$ to its peak of $77 \mathrm{~m} \mathrm{~s}^{-1}$. After reaching its peak, Maemi's intensity was sustained between category 4 and 5 for another $36 \mathrm{~h}$ as it traveled over the peripheral region of WOE-2 and WOE-3 (section 3). The CHIPS hindcast experiments show that without incorporating eddy information, Maemi's peak intensity is underestimated by one category (i.e., category 4 versus the ob- served category 5) and its intensity cannot be sustained as observed. With the incorporation of the eddy information (in satellite SSHA) into the hindcast, both peak intensity and intensity maintenance are improved. The CHIPS experiments and NPACNFS pretyphoon upperocean thermal profile suggest that the thick layer $(\geq 110-120 \mathrm{~m})$ of warm water $\left(\geq 26^{\circ} \mathrm{C}\right)$ in the eddy region effectively limits the typhoon-induced sea surface temperature cooling at the storm center. We suggest that the presence of a warm eddy can be regarded as an insulator between the tropical cyclone and deep, cold ocean water; therefore the negative feedback from the tropical cyclone's self-induced sea surface cooling is reduced. The presence of the eddy also helps to sustain Maemi's intensity at category 4 and above for another $36 \mathrm{~h}$ after its peak.

Meanwhile, observations from satellite cloud-penetrating microwave sea surface temperature measurements (TRMM and AMSR-E) independently support the aforementioned insulating effect owing to the warm eddy. In the warm eddy region, the observed tropical cyclone-induced sea surface cooling is generally around $0.5^{\circ} \mathrm{C}$, in contrast to the $2^{\circ} \mathrm{C}$ cooling outside the eddy region. Together with the previous three reported hurricane cases in the Gulf of Mexico, this study suggests that warm ocean eddies/features contribute to further greater peak intensity but are not necessary for rapid intensification. The presence of a warm eddy typically increases tropical cyclone intensity by one category, mostly from category 4 to 5 . Generally, rapid intensification is found during favorable atmospheric conditions, such as when the vertical shear is weak.

In this paper we have used the CHIPS model to demonstrate the first-order effect of the warm ocean eddy on the intensity evolution of Maemi. But we note that, 


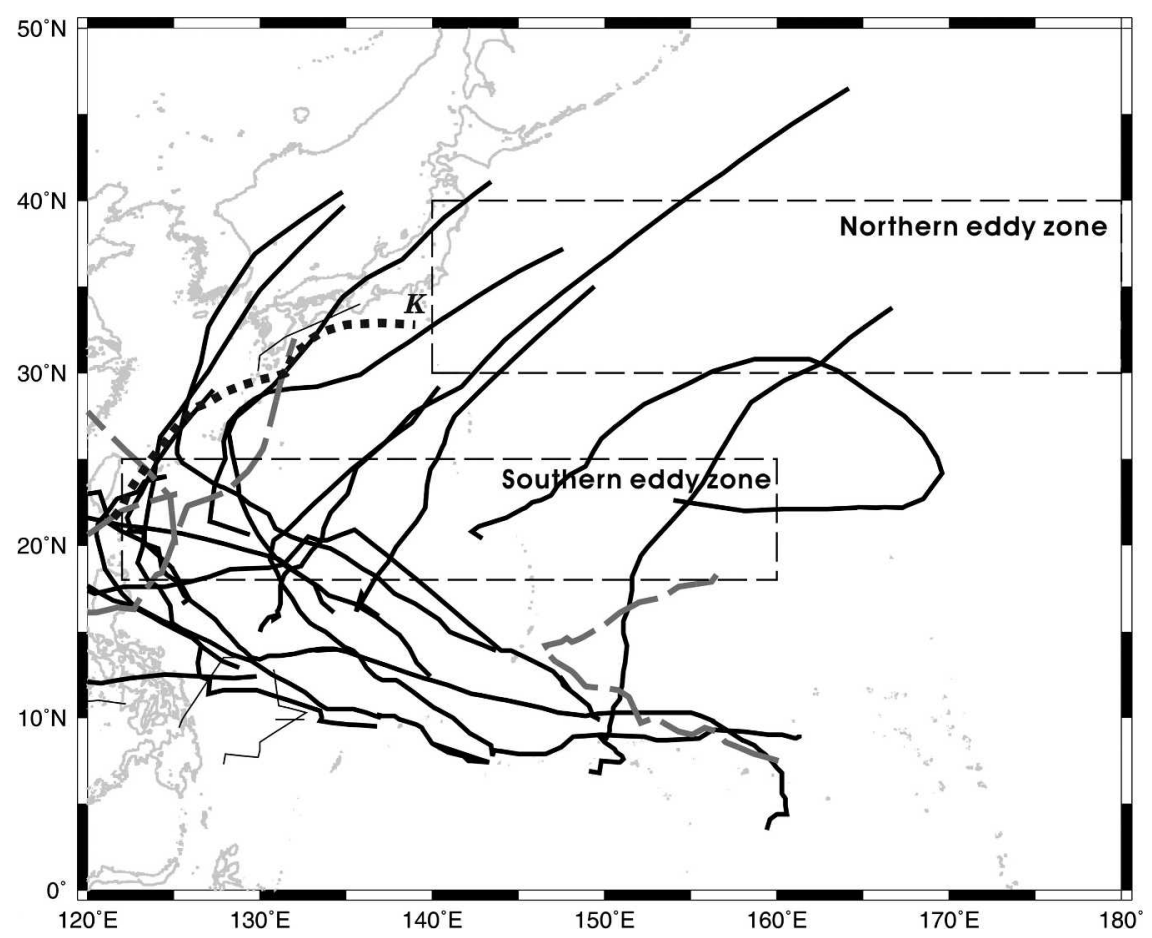

FIG. 11. Trajectories of typhoons (black lines)/tropical storm and depressions (long gray dashed line) in 2003 with the two eddy-rich zones (northern eddy zone and southern eddy zone in two dashed boxes) depicted. The location of the Kuroshio is denoted as $\mathrm{K}$ and shown with a short-dashed black line.

owing to the simplicity of the design of CHIPS, some important effects have been omitted, such as eddyrelated variability in the submixed-layer thermal stratification, three-dimensional eddy structure, freshwater flux ( $\mathrm{Li}$ et al. 1998), and horizontal advection by ocean currents. We also note that it will be interesting to assess how typhoons interact with cold ocean eddies, since these also exist in abundance in the two eddy-rich zones of the western North Pacific. The trajectories of tropical cyclones in 2003 and the locations of the the two eddy-rich zones (Fig. 11) also indicates that abundant tropical cyclones passed over ocean eddies in the western North Pacific, we believe that understanding tropical cyclone-eddy interaction is important for improving tropical cyclone intensity prediction in this region. We continue working with both simple models (such as CHIPS) and the more sophisticated GFDL hurricane-ocean coupled model (Bender and Ginis 2000) to systematically study more tropical cyclone cases in the western North Pacific and to thoroughly address the influence of ocean eddies on tropical cyclone intensity.

Acknowledgments. The authors wish to thank Dr. Dong-San Ko, Prof. Cheinway Hwang, Mr. Ricky Kao, and Dr. Yih Yang for providing some of the data and for their helpful discussions. Thanks also go to the Remote Sensing Systems for providing the TMI and AMSR-E data. Some major portion of the paper was drafted while the corresponding author was on a sabbatical visit at GFDL, Princeton University. Constructive discussions with Morris Bender, Isaac Held, Mark DeMaria, and Isaac Ginis, and helpful comments from the anonymous reviewers, are highly appreciated. This work is supported by Grants NSC 91-2119-M-002-032, NSC 92-2119-M-002-008-AP1, NSC 93-2111-M-002003, and NSC 93-2119-M-002-013-AP1.

\section{REFERENCES}

Bender, M. A., and I. Ginis, 2000: Real-case simulations of hurricane-ocean interaction using a high-resolution coupled model: Effects on hurricane intensity. Mon. Wea. Rev., 128, 917-946.

Bosart, L. F., C. S. Velden, W. E. Bracken, J. Molinari, and P. G. Black, 2000: Environmental influences on the rapid intensification of Hurricane Opal (1995) over the Gulf of Mexico. Mon. Wea. Rev., 128, 322-352.

Cione, J. J., and E. W. Uhlhorn, 2003: Sea surface temperature variability in hurricanes: Implications with respect to intensity change. Mon. Wea. Rev., 131, 1783-1796.

Emanuel, K. A., 1995: Sensitivity of tropical cyclones to surface exchange coefficients and a revised steady-state model incorporating eye dynamics. J. Atmos. Sci., 52, 3969-3976. 
1999: Thermodynamic control of hurricane intensity. $\mathrm{Na}$ ture, 401, 665-669.

- 2000: A statistical analysis of tropical cyclone intensity. Mon. Wea. Rev., 128, 1139-1152.

— C. C. DesAutels, C. Holloway, and R. Korty, 2004: Environmental control of tropical cyclone intensity. J. Atmos. Sci., 61, 843-858.

Fu, L. L., and A. Cazenave, Eds., 2001: Satellite Altimetry and Earth Sciences: A Handbook of Techniques and Applications. Academic Press, 463 pp.

— E. J. Christensen, C. A. Yamarone, M. Lefebvre, Y. Menard, M. Dorrer, and P. Escudier, 1994: TOPEX/POSEIDON mission overview. J. Geophys. Res., 99, 24 369-24 381.

Gallacher, P. C., R. Rotunno, and K. A. Emanuel, 1989: Tropical cyclogenesis in a coupled ocean-atmosphere model. Extended Abstracts, 18th Conf. on Hurricanes and Tropical Meteorology, San Diego, CA, Amer. Meteor. Soc., 121-122.

Goni, G. J., and J. A. Trinanes, 2003: Ocean thermal structure monitoring could aid in the intensity forecast of tropical cyclones. Eos, Trans. Amer. Geophys. Union, 84, 573-580.

_ , P. Black, and J. Trinanes, 2003: Using satellite altimetry to identify regions of hurricane intensification. AVISO Newsletter, No. 9, CNES, Paris, France, 19-20.

Hong, X., S. W. Chang, S. Raman, L. K. Shay, and R. Hodur, 2000: The interaction between Hurricane Opal (1995) and a warm core ring in the Gulf of Mexico. Mon. Wea. Rev., 128, 1347-1365.

Hwang, C., C. R. Wu, and R. Kao, 2004: TOPEX/Poseidon observations of mesoscale eddies over the subtropical countercurrent: Kinematic characteristics of an anticyclonic eddy and of a cyclonic eddy. J. Geophys. Res., 109, C08013, doi:10.1029/ 2003JC002026.

Kaplan, J., and M. DeMaria, 2003: Large-scale characteristics of rapidly intensifying tropical cyclones in the North Atlantic basin. Wea. Forecasting, 18, 1093-1108.

Ko, D. S., R. H. Preller, G. A. Jacobs, T. Y. Tang, S. F. Lin, 2003: Transport reversals at Taiwan Strait during October and November 1999. J. Geophys. Res., 108, 3370, doi:10.1029/ 2003JC001836.

Lee, I.-H., 2003: Meso-scale eddies in the western Pacific and their influences on the Kuroshio. Ph.D. thesis, Institute of Oceanography, National Taiwan University, 101 pp.
Levitus, S., 1982: Climatological Atlas of the World Ocean. NOAA Prof. Paper 13, 173 pp. and 17 microfiche.

Li, X., C.-H. Sui, D. Admec, and K. M. Lau, 1998: Impact of precipitation in the upper ocean in the western Pacific warm pool during TOGA-COARE. J. Geophys. Res., 103 (C3), 5347-5359.

Marks, F. D., and L. K. Shay, and PDT-5, 1998: Landfalling tropical cyclones: Forecast problems and associated research opportunities. Bull. Amer. Meteor. Soc., 79, 305-323.

Pickard, G. L., and W. J. Emery, 1990: Descriptive Physical Oceanography. Pergamon Press, 320 pp.

Price, J. F., 1981: Upper ocean response to a hurricane. J. Phys. Oceanogr., 11, 153-175.

Qiu, B., 1999: Seasonal eddy field modulation of the North Pacific Subtropical Countercurrent: TOPEX/Poseidon observations and theory. J. Phys. Oceanogr., 29, 1670-1685.

Richard, H. B., 1981: Gulf Stream cold-core rings: Their physics, chemistry, and biology. Science, 212, 1091-1100.

Roemmich, D., and J. Gilson, 2001: Eddy transport of heat and thermocline waters in the North Pacific: A key to interannual/decadal climate variability? J. Phys. Oceanogr., 31, 675687.

Schade, L. R., 1997: A physical interpretation of SST-feedback. Preprints, 22d Conf. on Hurricanes and Tropical Meteorology, Fort Collins, CO, Amer. Meteor. Soc., 439-440.

_ and K. A. Emanuel, 1999: The ocean's effect on the intensity of tropical cyclones: Results from a simple coupled atmosphere-ocean model. J. Atmos. Sci., 56, 642-651.

Shay, L. K., G. J. Goni, and P. G. Black, 2000: Effects of a warm oceanic feature on Hurricane Opal. Mon. Wea. Rev., 128, 1366-1383.

Wentz, F. J., C. Gentemann, D. Smith, and D. Chelton, 2000: Satellite measurements of sea surface temperature through clouds. Science, 288, 847-850.

__ _ _ - and P. Ashcroft, 2003: On-orbit calibration of AMSR-E and the retrieval of ocean products. Preprints, 12th Conf. on Satellite Meteorology and Oceanography, Long Beach, CA, Amer. Meteor. Soc., CD-ROM, P5.9.

Yasuda, I., K. Okuda, and M. Hirai, 1992: Evolution of a Kuroshio warm-core ring-Variability of the hydrographic structure. Deep-Sea Res., 39, 131-161. 